\title{
Electrospray Ionization Mass Spectrometric Detection of Self-Assembly of a Crown Ether Complex Directed by $\pi$-Stacking Interactions
}

\author{
Courtney L. Sherman and Jennifer S. Brodbelt \\ Department of Chemistry and Biochemistry, University of Texas at Austin, Austin, Texas, USA
}

\author{
Alan P. Marchand and Bhaskar Poola \\ Department of Chemistry, University of North Texas, Denton, Texas, USA
}

\begin{abstract}
The self-assembly of ligand-metal-ligand sandwich complexes involving a novel quinoxalinecontaining crown ether, 1, was studied by electrospray ionization mass spectrometry (ESI-MS). Donor-acceptor $\pi$-stacking interactions between the electron-poor quinoxaline group of $\mathbf{1}$ and electron-rich benzene groups from benzo- or dibenzo-18-crown-6 were found to significantly enhance the formation of mixed-ligand sandwich complexes with a free energy gain of up to $17 \mathrm{~kJ} / \mathrm{mol}$ relative to sandwich formation involving macrocycles without such aromatic functionalities. The relative intensities of the sandwich complexes were greatest with the alkali metals $\mathrm{Na}^{+}, \mathrm{K}^{+}$, and $\mathrm{Rb}^{+}$as well as with the ammonium ion in equimolar concentrations with the@nacrocycles. (he@referential@ormation@f(®he@nixed-ligand@andwich@omplexes@emonstrated that donor-acceptor $\pi$-stacking interactions contribute to the assembly of molecular structures and can be monitored by ESI-MS. (J Am Soc Mass Spectrom 2005, 16, 1162-1171) (C) 2005 American Society for Mass Spectrometry
\end{abstract}

$I^{2}$ $\mathrm{n}$ recent years, molecular self-assembly has become a key tool for developing novel chemical structures. Applications as diverse as patterned deposition of metallic@monolayers@[1],(creation@of@ordered@lightharvesting@arrays@2], (and@reation@of@new@biological materials based on self assembled peptide structures [3], @have@evolutionized@he@evelopment@f@naterials with nanoscale features. Various types of chemical interactions have been used to direct the assembly of individual subunits into the desired products. In the present report, we present electrospray ionization mass spectrometry (ESI-MS) results on a novel crown ether which demonstrate that donor-acceptor $\pi$-stacking interactions can be used to direct the self-assembly of noncovalent macrocycle-metal complexes.

For probing metal complexation of macrocyclic systems, ESI-MS has proven to be an invaluable tool. Since ESI@s@apable@f@ransferring@ven@ery@veakly@ound noncovalent complexes to the gas phase, mass spectrometry can be used to qualitatively and quantitatively evaluate the binding selectivities of the hosts or the relative binding constants of the resulting host-guest complexes@[4@22].@Furthermore,@many@studies@have demonstrated that the results of ESI-MS analysis of these host-guest complexes correlate well with mea-

Published online May 25, 2005

Address reprint requests to Dr. J. S. Brodbelt, Department of Chemistry and Biochemistry, University of Texas at Austin, 1 University Station A5300, Austin, TX 78712-0165, USA. E-mail: jbrodbelt@mail.utexas.edu surements@f@the@equilibriađin@solution@8,(9), (14@17]. Crown ether-metal complexes, in particular, have been the subject of much study, and the binding properties of many types of these macrocyclic complexes have been

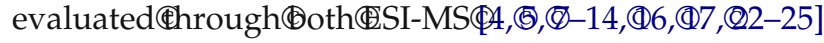
and@more@raditional@olution@analysesథ26@31].@While most such studies have focused on the 1:1 crown ether:metal complexes, 2:1 crown ether:metal "sandwich"@omplexes@re@vell@known@23-25,(228@31]@and have@een@tudied@uccessfully@y@SI-MSథ23-25].

Although binding of the second ligand in a ligandmetal-ligand sandwich complex in solution is typically not as strong as for the first ligand for unsubstituted crown@ethers@27], Gt@is@xpected@hat@he@ddition@f certain functional groups on the macrocycle could enhance the formation of sandwich complexes. An analogous result has been observed for the formation of bis-crown ether-metal complexes studied by ESI-MS [13,(23,(28].థror@hese@nacrocycles, (he \$reorganization offered by the covalently linked crown ethers results in very strong metal complexation in which the metal cation is simultaneously coordinated by both crown ethers.

Rather than rely on covalently linked structures, such as those used in bis-crown ethers, other chemical interactions must be leveraged to create sandwich complexes which can self-assemble. $\pi$-Stacking interactions, present in many biological systems and having demonstrated utility in strengthening other types of molecular interactions\$32-35],@epresent@@ovel@neans@f@nhanc- 


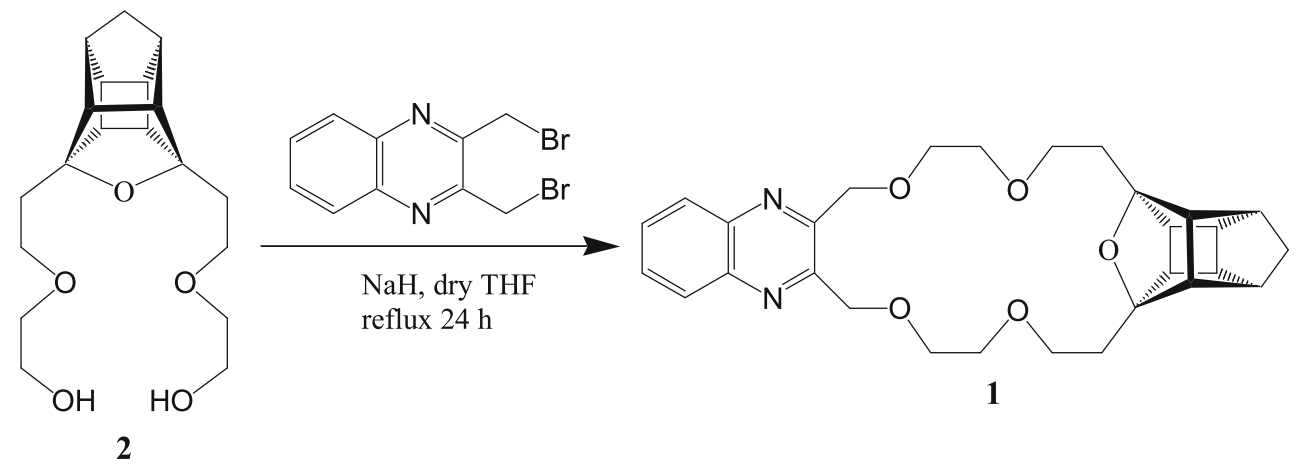

Scheme 1

ing the formation of macrocycle-metal sandwich complexes. In contrast to the well studied interactions between@metal@ons@nd@i-orbital@ystems $₫ 36 @ 38$, $($ hhe inclusion of aromatic moieties on the macrocycles in this report is expected to result in $\pi$-stacking interactions between the $\pi$-orbital systems on different macrocycles. These interactions should enhance the formation of sandwich complexes when the $\pi$-orbitals have appropriate overlap by allowing the detection of sandwich complexes incorporating larger macrocycles or smaller metal ions, ones not typically observed.

$\pi$-Stacking interactions can be further enhanced through the presence of donor-acceptor interactions between the $\pi$-orbitals. Including electronegative heteroatoms such as nitrogen or oxygen in an aromatic system creates an electron-deficient $\pi$-system in a manner similar to the effect of including an electronwithdrawing@ubstituent@n@he@romatic@ing \$32].đhe net result is a change in the polarization of the $\pi$-orbitals relative to an aromatic moiety without such heteroatoms, causing an additional attractive force as some electron density from the electron-rich $\pi$-system is donated to the electron-deficient $\pi$-system, strengthen-

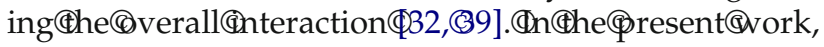
an electron-deficient quinoxaline moiety is incorporated into a crown ether macrocycle, $\mathbf{1}$ (shown in Scheme 1), to enhance the sandwich complex formation with benzo-crown ethers as a potential building block for self-assembled structures. The size selectivity of sandwich formation is evaluated based on comparative studies involving different metal ions, and the impact of the donor-acceptor interactions is investigated by use of a variety of reference macrocycles. Additionally, the impact of various solvent systems on sandwich complex formation is studied.

\section{Experimental}

\section{Instrumentation}

Mass spectra were collected on a LCQ Duo quadrupole ion trap mass spectrometer equipped with an ESI source (ThermoFinnigan, San Jose, CA). Instrumental parameters were optimized for transmission of the 2:1 crown ether:metal complexes, and the heated capillary was kept at $80^{\circ} \mathrm{C}$ to minimize in-source fragmentation. The same parameters were used for all solutions to minimize instrumental deviations. Presented spectra are averages of one hundred scans. High-resolution mass spectral data reported herein for Compound 1 were obtained by personnel at the Mass Spectrometry Facility at the Department of Chemistry and Biochemistry, University of Texas at Austin, by using a ZAB-E double sector high-resolution mass spectrometer (Micromass, Manchester, United Kingdom) that was operated in the chemical ionization mode. Elemental microanalysis of $\mathbf{1}$ was performed by personnel at $\mathrm{M}-\mathrm{H}-\mathrm{W}$ Laboratories, Inc., Phoenix, AZ.

\section{Synthesis of 1}

The quinoxaline-containing caged 19-crown-5, 1, was prepared by the base-promoted reaction of 2,3-bis(bromomethyl)quinoxaline with 2 as shown in Scheme 1. A mixture of $\mathrm{NaH}$ (obtained as a $60 \%$ dispersion in mineral oil, $400 \mathrm{mg}, 9.0 \mathrm{mmol})$ and dry THF $(40 \mathrm{~mL})$ was refluxed with stirring under argon. To this refluxing mixture was added dropwise with stirring a solu-

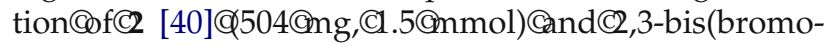
methyl)quinoxaline (498 mg, $1.6 \mathrm{mmol})$ in dry THF (15 $\mathrm{mL})$. After the addition of reagents had been completed, the resulting mixture was refluxed under argon for $24 \mathrm{~h}$. The stirred reaction mixture was allowed to cool gradually to ambient temperature and then was quenched via careful dropwise addition of water $(2 \mathrm{~mL})$ until a clear solution resulted. An additional quantity of water $(15 \mathrm{~mL})$ was added, and the resulting aqueous solution was extracted with EtOAc $(3 \times 20 \mathrm{~mL})$. The combined organic layers were washed with brine $(20 \mathrm{~mL})$, dried $\left(\mathrm{Na}_{2} \mathrm{SO}_{4}\right)$ and filtered, and the filtrate was concentrated in vacuo. The residue was purified via column chromatography on silica gel by eluting with $40 \%$ EtOAchexane. Workup of the chromatography fractions thereby obtained afforded crude 1 (335 mg, 46\%); fractional recrystallization of this material from EtOAc afforded pure 1 as a colorless microcrystalline solid: $\mathrm{mp}$ 140-141 C; IR (KBr) 2961 (m), 2941 (m), 2894 (m), 2865 (m), 2850 (m), 1295 (m), 1118 (vs), 1102 (vs), 978 (s), 909 (s), $771 \mathrm{~cm}^{-1}(\mathrm{~s}) ;{ }^{1} \mathrm{H} \mathrm{NMR}\left(\mathrm{CDCl}_{3}\right) \delta 1.43\left(\mathrm{AB}, \mathrm{J}_{\mathrm{AB}}=10.3\right.$ 
$\mathrm{Hz}, 1 \mathrm{H}), 1.75\left(\mathrm{AB}, \mathrm{J}_{\mathrm{AB}}=10.3 \mathrm{~Hz}, 1 \mathrm{H}\right), 1.94-2.01(\mathrm{~m}, 4$ $\mathrm{H}), 2.32(\mathrm{br} \mathrm{s}, 2 \mathrm{H}), 2.51-2.60(\mathrm{~m}, 6 \mathrm{H}), 3.64-3.82(\mathrm{~m}, 12$ $\mathrm{H}), 4.99(\mathrm{~s}, 4 \mathrm{H}), 7.68-7.73$ (upfield half of a centrosymmetric AA'BB' spin pattern, $2 \mathrm{H}$ ), 8.04-8.09 (lowfield half of a centrosymmetric $\mathrm{AA}^{\prime} \mathrm{BB}^{\prime}$ spin pattern, $2 \mathrm{H}$ ); ${ }^{13} \mathrm{C}$ NMR $\left(\mathrm{CDCl}_{3}\right) \delta 32.2(\mathrm{t}), 41.3(\mathrm{~d}), 43.4(\mathrm{t}), 43.8(\mathrm{~d})$, $48.0(\mathrm{~d}), 58.9(\mathrm{~d}), 68.0(\mathrm{t}), 70.0(\mathrm{t}), 71.1(\mathrm{t}), 72.5(\mathrm{t}), 94.3(\mathrm{~s})$, 128.9 (d), 129.7 (d), 141.1 (s), 152.2 (s); exact mass (CI HRMS); calculated for $\mathrm{C}_{29} \mathrm{H}_{34} \mathrm{~N}_{2} \mathrm{O}_{5}:\left(\mathrm{M}_{\mathrm{r}}+\mathrm{H}\right)^{+} \mathrm{m} / \mathrm{z}$ 491.2546; found: $\left(\mathrm{M}_{\mathrm{r}}+\mathrm{H}\right)^{+} \mathrm{m} / \mathrm{z}$ 491.2539; calculated for $\mathrm{C}_{29} \mathrm{H}_{34} \mathrm{~N}_{2} \mathrm{O}_{5}: \mathrm{C}, 71.00 ; \mathrm{H}, 7.00$; found: $\mathrm{C}, 71.24 ; \mathrm{H}, 6.80$.

\section{Reagents}

18-Crown-6, aza-18-crown-6, benzo-18-crown-6, dibenzo18-crown-6, and dicyclohexano-18-crown-6 and the $\mathrm{RbCl}$, $\mathrm{CsCl}, \mathrm{SrCl}_{2}$, and $\mathrm{BaCl}_{2}$ salts were obtained from the Aldrich Chemical Co. (Milwaukee, WI). $\mathrm{NaCl}, \mathrm{KCl}$, and $\mathrm{NH}_{4} \mathrm{Cl}$ salts were obtained from EM Science (Gibbstown, $\mathrm{NJ}$ ). $\mathrm{AgNO}_{3}$ was obtained from Alfa Aesar (Ward Hill, MA). Aside from the aza-18-crown-6 and dicyclohexano18-crown-6, which had purities of 95 and $90 \%$, respectively, all reagents were of at least $98 \%$ purity. All were used without further purification. Analyzed solutions contained 1, an additional macrocycle, and a salt in a 1:1:1 ratio with concentrations of $5 \times 10^{-5} \mathrm{M}$ using spectroscopic grade OmniSolv methanol (EM Science) as the solvent. Solvent studies were performed using 1:1:1 solutions as described above using as solvents 1:1 water: methanol (water purified in-house, OmniSolv methanol). Omnisolv methanol, HPLC grade acetonitrile were purchased from Fisher Scientific (Pittsburgh, PA), and Optima grade chloroform, also from Fisher.

\section{Results and Discussion}

To evaluate the importance of $\pi$-stacking interactions in the self-assembly process, ESI-MS was used to examine solutions containing an equimolar quantity of $\mathbf{1}$, a second ligand, and a cation. For each solution, the distribution of complexes containing a single macrocycle and cation (i.e., 1:1 complexes), two of the same macrocycles with one cation (i.e., 2:1 complexes or homo-ligand sandwiches), or two different macrocycles with one cation (i.e., mixed-ligand sandwich complexes) was monitored. The distribution of complexes was then correlated with the structures of the macrocycles, the presence of appropriate donor-acceptor interactions, and the type of cation.

As a semi-quantitative means of evaluating the contribution of $\pi$-stacking towards any observed enhancement in the amount of the mixed-ligand complex, a hypothetical ligand exchange reaction was considered:

$$
\mathrm{A}_{2} \mathrm{M}^{+}+\mathrm{B}_{2} \mathrm{M}^{+} \Leftrightarrow 2 \mathrm{ABM}^{+}
$$

where A and B are two different macrocyclic ligands and $\mathrm{M}$ is the cation bound between the ligands. Regardless of whether or not the direct ligand exchange reaction is kinetically feasible, if the system is at equilibrium, the concentrations of the complexes must adhere to the thermodynamic equilibrium:

$$
\mathrm{K}_{\mathrm{EX}}=\frac{\left[\mathrm{ABM}^{+}\right]^{2}}{\left[\mathrm{~A}_{2} \mathrm{M}^{+}\right]\left[\mathrm{B}_{2} \mathrm{M}^{+}\right]}
$$

where $K_{\mathrm{EX}}$ is the equilibrium constant for Reaction 1. ESI mass spectral intensities, $\mathrm{I}_{\mathrm{X}}$, relate to solution concentrations through the use of an ESI efficiency correction, $\mathrm{C}_{\mathrm{X}}$ :

$$
[\mathrm{X}]=\mathrm{C}_{\mathrm{X}} \mathrm{I}_{\mathrm{X}}
$$

$\mathrm{K}_{\mathrm{EX}}$ can then be calculated directly from the ESI mass spectral intensities, $\mathrm{I}_{\mathrm{X}}$, of the complex ions:

$$
\mathrm{K}_{\mathrm{EX}}=\left(\frac{\mathrm{C}_{\mathrm{ABM}^{+}}{ }^{2}}{\mathrm{C}_{\mathrm{A}_{2} \mathrm{M}^{+}} \mathrm{C}_{\mathrm{B}_{2} \mathrm{M}^{+}}}\right)\left(\frac{\mathrm{I}_{\mathrm{ABM}^{+}}{ }^{2}}{\mathrm{I}_{\mathrm{A}_{2} \mathrm{M}^{+}} \mathrm{I}_{\mathrm{B}_{2} \mathrm{M}^{+}}}\right)
$$

Previous studies suggest that ESI efficiencies for similar host-guest complexes, including ones involving macrocyles or even large biological molecules, are often close

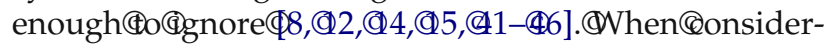
ing this ligand exchange reaction, even if the ESI efficiencies of the different sandwich complexes were very different, they would have only minimal influence on the measured $\mathrm{K}_{\mathrm{EX}}$ values. Since the mixed-ligand sandwich complex contains one ligand from each of the two homo-ligand complexes, its ESI efficiency should be somewhere midway between the efficiencies of the homo-ligand complexes. As a result, the ratio of ESI efficiencies in eq 4 is near unity, allowing simplification of eq 4 into:

$$
\mathrm{K}_{\mathrm{EX}}=\frac{\mathrm{I}_{\mathrm{ABM}^{+}}{ }^{2}}{\mathrm{I}_{\mathrm{A}_{2} \mathrm{M}^{+}} \mathrm{I}_{\mathrm{B}_{2} \mathrm{M}^{+}}}
$$

From $\mathrm{K}_{\mathrm{EX}}$, the Gibb's free energy of the ligand exchange reaction can be calculated from:

$$
\Delta \mathrm{G}_{\mathrm{EX}}=-\mathrm{RT} \ln \mathrm{K}_{\mathrm{EX}}
$$

where $\mathrm{R}$ is the ideal gas constant and $\mathrm{T}$ is the temperature. For an electrospray experiment, $\mathrm{T}$ is simply the room temperature. This change in free energy represents the extent to which a mixed-ligand complex is energetically favored relative to the two homo-ligand complexes. The $\Delta \mathrm{G}_{\mathrm{EX}}$ values in our study are calculated from ESI mass spectra obtained for solutions containing two different macrocycles, thus allowing direct comparison of the abundances of each homo-ligand sandwich complex to the single mixed-ligand sandwich complex and providing a self-consistent standardization of the spectra. Large positive $\Delta \mathrm{G}_{\mathrm{EX}}$ values signify that the homo-ligand complexes are favored, near-zero values mean that the homo-ligand and mixed-ligand com- 


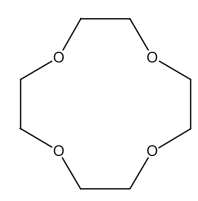

12-crown-4 (176 Da)

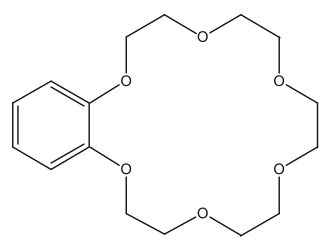

benzo-18-crown-6 (312 Da)

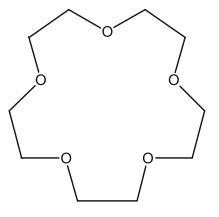

15-crown-5 (220 Da)

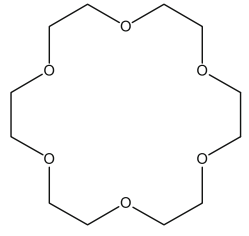

18-crown-6 (264 Da)

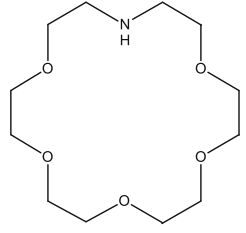

aza-18-crown-6 (263 Da)

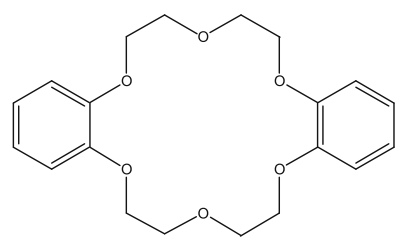

dibenzo-18-crown-6 (360 Da)

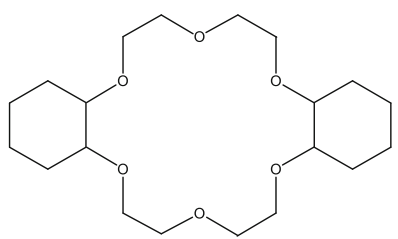

dicyclohexano-18-crown-6 (372 Da)

Scheme 2

plexes are equally favored, and large negative values reflect a strong preference for formation of mixedligand sandwich complexes.

To differentiate the importance of $\pi$-stacking interactions from other types of electrostatic interactions, several reference macrocycles were chosen for comparison of their interactions with $\mathbf{1}$ (see Scheme 2). 18Crown-6 and aza-18-crown- 6 were selected because these ligands have no functional groups capable of interacting with the quinoxaline moiety of $\mathbf{1}$. Benzo-18crown- 6 and dibenzo-18-crown- 6 were selected as reference ligands because they have similar metal binding properties, but their aromatic substituents could promote $\pi$-stacking interactions with $\mathbf{1}$. Dicyclohexano-18crown-6 has a similar size and shape to that of dibenzo18-crown-6 but its substituents are not aromatic, thus allowing a way to evaluate the possibility that favorable steric interactions enhance sandwich formation rather than interactions between the aromatic groups. Admittedly, the three-dimensional structure of cyclohexane bears little resemblance to benzene, but as substituents on 18-crown-6 both would add a similar degree of structural rigidity and have approximately the same degree of "bulk" extending from the crown ether.

As nearly ideal singly-charged spheres, the alkali metals $\mathrm{Li}^{+}, \mathrm{Na}^{+}, \mathrm{K}^{+}, \mathrm{Rb}^{+}$, and $\mathrm{Cs}^{+}$were analyzed with all combinations of macrocycles in solution to evaluate the periodic trends in the size-selectivity of sandwich formation. Other metals studied included the alkaline earths $\mathrm{Sr}^{2+}$ and $\mathrm{Ba}^{2+}$, chosen because their ionic radii are similar to $\mathrm{Na}^{+}$and $\mathrm{K}^{+}$yet with much greater charge densities, as well as $\mathrm{Ag}^{+}$which is known to have particular affinity for nitrogen-containing compounds

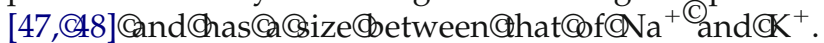
Finally, formation of sandwich complexes with $\mathrm{NH}_{4}{ }^{+}$, a nonmetallic ion with a size similar to that of $\mathrm{Rb}^{+}$, were examined in order to evaluate the activity of the selfassembly process over a wider range of cations.
As an initial control experiment, $\mathbf{1}$ was analyzed alone@in@methanol@as@shown@in@Figure@1a.CIn@this spectrum, protonated 1 was the dominant ion, and lesser amounts of $\left(\mathbf{1}+\mathrm{Na}^{+}\right)$and $\left(\mathbf{1}+\mathrm{K}^{+}\right)$complexes were also observed, presumably because of the presence of background solvent contaminants or ionic contaminantsథeached $₫$ rom $\oplus$ he@lassware@sed $($ Figure $₫ a)$. The complete absence of sandwich complexes demonstrated that the levels of ionic contaminants in the solvents used are not sufficient to promote sandwich
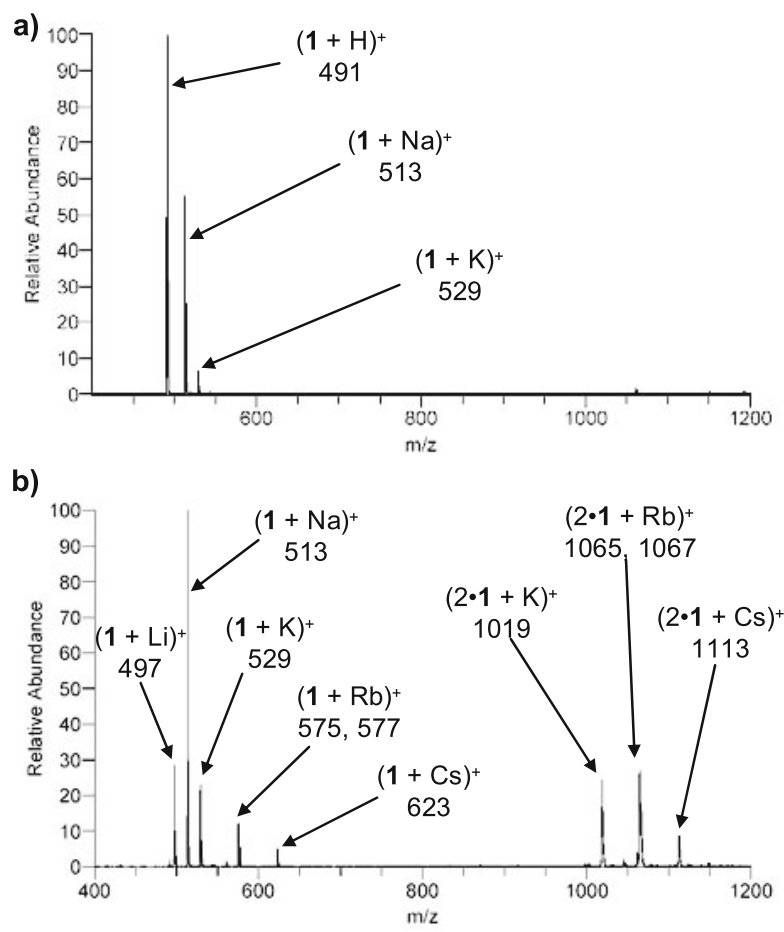

Figure 1. ESI-mass spectrum of (a) $\mathbf{1}$ in methanol, and (b) $\mathbf{1}$ with equimolar $\mathrm{LiCl}, \mathrm{NaCl}, \mathrm{KCl}, \mathrm{RbCl}$, and $\mathrm{CsCl}$ in methanol. 
Table 1. Reported binding constants in methanol for the first and second attachment of either 12-crown-4 (A) or 15-crown-5 (B) to $\mathrm{Na}^{+}$or $\mathrm{K}^{+}$and free energy change for the ligand exchange reaction for solutions containing both ligands with one of the cations calculated from the ESI-MS measurements. Errors reflect statistical deviation over three replicate measurements

\begin{tabular}{llllrr}
\hline & \multicolumn{4}{c}{$\log \mathrm{K}^{\mathrm{a}}$} & \\
\cline { 2 - 5 } Cation & $\mathrm{MA}$ & $\mathrm{MA}_{2}$ & $\mathrm{MB}$ & $\mathrm{MB}_{2}$ & $\begin{array}{r}\Delta \mathrm{G}_{\mathrm{EX}} \\
(\mathrm{kJ} / \mathrm{mol})\end{array}$ \\
\hline \hline $\mathrm{Na}^{+}$ & 1.5 & 2.2 & 3.32 & 2.5 & $-0.5 \pm 0.2$ \\
$\mathrm{~K}^{+}$ & 1.60 & $1.45^{\mathrm{b}}$ & 3.5 & 2.5 & $-1.5 \pm 0.1$
\end{tabular}

${ }^{\text {a}}$ From reference [27].

${ }^{b}$ From reference [49].

complex formation, eliminating the possibly of contaminant-related errors.

ESI-MS analysis of $\mathbf{1}$ alone in solution with alkali metal ions added at equimolar concentrations indicates that in the formation of 1:1 macrocycle:metal complexes, 1 has a greater affinity for $\mathrm{Na}^{+}$over that of $\mathrm{Li}^{+}$, $\mathrm{K}^{+}, \mathrm{Rb}^{+}$, or $\mathrm{Cs}^{+}$, assuming similar electrospray efficien-

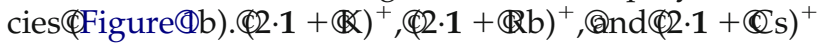
sandwich complexes are also formed, but sandwiches incorporating $\mathrm{Li}^{+}$or $\mathrm{Na}^{+}$are not observed because the smaller sizes of $\mathrm{Li}^{+}$and $\mathrm{Na}^{+}$allow them to be encapsulated within the cavity of $\mathbf{1}$, thus preventing the favorable coordination of a second ligand. The larger sizes of $\mathrm{K}^{+}, \mathrm{Rb}^{+}$, and $\mathrm{Cs}^{+}$make them perch partially out of the cavity of $\mathbf{1}$ and permit the complexation of a second ligand.

\section{Analysis of Model Sandwich Complexes}

To confirm the validity of the approach outlined above for evaluating the formation of mixed-ligand sandwich complexes, two model systems were evaluated: sandwich complexes of 12-crown-4, 15-crown-5, and either $\mathrm{Na}^{+}$or $\mathrm{K}^{+}$. Both ligands are known to form homoligand@andwich@omplexes@eadily@27].థFurthermore, these two ligands are both small and likely have little interaction with the adjacent ligand in a sandwich complex. In an ideal case, if the binding of ligands to a metal were completely independent, the first and second binding constants, $\mathrm{K}_{1}$ and $\mathrm{K}_{2}$, would be equal. As seen@n@Tableđ,@or@ach@f@heseđigands@with@ither $\mathrm{Na}^{+}$or $\mathrm{K}^{+}, \mathrm{K}_{1}$ and $\mathrm{K}_{2}$ values are close to each other. In the absence of any specific interactions between the ligands, the binding in the analogous mixed-ligand sandwich complexes should be nearly independent as well. As a consequence, there should be no significant difference energetically between the homo- and mixedligand complexes in a ligand exchange reaction like in eq 1 . In other words, with 12-crown-4, 15-crown-5, and either $\mathrm{Na}^{+}$or $\mathrm{K}^{+}$, the value of $\Delta \mathrm{G}_{\mathrm{EX}}$ measured from the ESI mass spectra and calculated with eq 6 should be

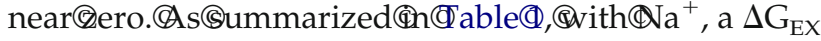
of $-0.5 \mathrm{~kJ} / \mathrm{mol}$ was measured, and for $\mathrm{K}^{+}, \Delta \mathrm{G}_{\mathrm{EX}}$ was $-1.5 \mathrm{~kJ} / \mathrm{mol}$, with both values validating our approach.

\section{Sandwich Complexes of Dibenzo-18-Crown-6 with Different Macrocycles}

As a first step towards evaluating the propensity of the various crown ethers to form mixed-ligand sandwich complexes, ESI mass spectra were collected for mixtures of dibenzo-18-crown-6, $\mathrm{KCl}$, and various other reference macrocycles, all crown ethers. In these spectra, and all others used for quantitative measurements of the sandwich complexes, the mass ranges were restricted to the region containing the sandwich to avoid spacecharge effects in the ion trap from the often abundant 1:1 complexes. From these spectra, the free energy of each ligand exchange reaction between the mixed- and homo-ligand complexes was calculated using eq 6 and listed@n@able@2.@f@he@ive@ther@rown@ther@igands evaluated, four yielded $\Delta G_{E x}$ values near zero, indicating nearly equal preference for formation of both the homo- and mixed-ligand complexes and suggesting the lack of any special ligand interactions that specifically favor formation of mixed-ligand complexes. The smaller size of 15-crown-5 prevents it from fully encapsulating $\mathrm{K}^{+}$, thus allowing the formation of both mixedligand and homo-ligand complexes in the presence of dibenzo-18-crown-6 For experiments involving aza-18crown- 6 and dibenzo-18-crown- 6 , the amino proton on aza-18-crown-6 introduces a degree of electrostatic repulsion between the crown and the metal, thus preventing complete encapsulation of $\mathrm{K}^{+}$and allowing formation of stable mixed-ligand complexes. With either dicyclohexano-18-crown-6 or benzo-18-crown-6, the substituents make both ligands more rigid, resulting in no significant difference in stability of the homo-ligand complexes relative to the mixed-ligand complexes as evidenced by the $\Delta \mathrm{G}_{\mathrm{Ex}}$ yalues(ear@ero $($ Table(Q).(None of these four ligands displayed any special enhancement in the formation of mixed-ligand complexes with $\mathrm{K}^{+}$and dibenzo-18-crown-6, in striking contrast to the

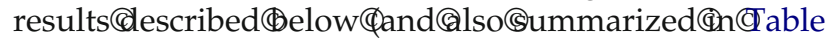
2)థor@andwich@ormation@involving@igand@.

The one notable exception in the propensity for formation of mixed-ligand sandwich complexes was for the experiments involving dibenzo-18-crown-6 and 18crown- 6 with $\mathrm{K}^{+}$, in which the spectra exhibited a

Table 2. Free energy change for the ligand exchange reaction for solutions of either 1 or dibenzo-18-crown- $6, \mathrm{~K}^{+}$and a second macrocycle. Errors reflect statistical deviation over three replicate measurements

\begin{tabular}{lcc}
\hline & \multicolumn{2}{c}{$\Delta \mathrm{G}_{\mathrm{EX}}(\mathrm{kJ} / \mathrm{mol})$} \\
\cline { 2 - 3 } Second macrocycle & 1 & $\begin{array}{c}\text { Dibenzo-18- } \\
\text { crown-6 }\end{array}$ \\
\hline \hline 15-Crown-5 & $8.6 \pm 0.8$ & $0.0 \pm 0.7$ \\
18-Crown-6 & $7.2 \pm 0.8$ & $11 \pm 1$ \\
Aza-18-Crown-6 & $7.6 \pm 0.2$ & $0.0 \pm 0.5$ \\
Dicyclohexano-18-crown-6 & $3.74 \pm 0.08$ & $1.3 \pm 1.3$ \\
Benzo-18-crown-6 & $-8.57 \pm 0.03$ & $-0.7 \pm 0.3$ \\
Dibenzo-18-crown-6 & $-7.8 \pm 0.1$ & - \\
\hline
\end{tabular}


marked preference against formation of the mixedligand complexes [i.e., (dibenzo-18-crown-6 + 18crown- $\left.6+\mathrm{K}^{+}\right)$], with a $\Delta \mathrm{G}_{\mathrm{EX}}$ value of $11 \mathrm{~kJ} / \mathrm{mol}$ calculated from the mass spectrum. 18-Crown- 6 is both large enough and flexible enough to encapsulate the potassium cation, thus prohibiting the coordination of a second ligand and quenching the formation of sandwich complexes.

\section{Sandwich Complexes Involving 1 with Different Macrocycles}

To determine the degree of enhancement in the formation of mixed-ligand sandwich complexes attributable to $\pi$-stacking interactions, solutions containing $\mathrm{KCl}, \mathbf{1}$ and various other reference macrocycles were analyzed. The@ESI@mass@pectra@hown@inđigure@2@isplay@he types of product ion distributions observed upon analysis of solutions containing $\mathbf{1}$, a second macrocycle, and an alkali metal salt, all at equimolar concentrations. For

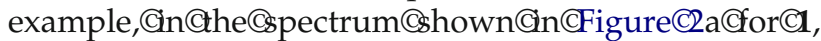
18-crown-6, and $\mathrm{KCl}$, the homo-ligand $(2 \cdot 1+\mathrm{K})^{+}$ complex is abundant, but the abundances of the sandwich complexes containing 18-crown-6, i.e., (2-18crown- $6+\mathrm{K})^{+}$and $(1+18 \text {-crown- } 6+\mathrm{K})^{+}$, are very low. The $\Delta \mathrm{G}_{\mathrm{EX}}$ value calculated from this mass spec-

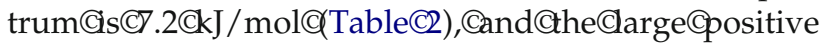
value conveys the preference for formation of the homo-ligand $(2 \cdot \mathbf{1}+\mathrm{K})^{+}$complexes over the mixedligand $(\mathbf{1}+18 \text {-crown- } 6+\mathrm{K})^{+}$complexes. When the solution containing 1 dibenzo-18-crown- 6 and $\mathrm{K}^{+}$was analyzed $₫$ Figure $(2 b), @$ he@nixed@igand@omplex, $₫ 1+$ dibenzo-18-crown- $6+\mathrm{K})^{+}$, dominated the spectrum. Its greater abundance relative to the homo-ligand complexes, $(2 \cdot \text { dibenzo-18-crown- } 6+\mathrm{K})^{+}$and $(2 \cdot 1+\mathrm{K})^{+}$, results in a $\Delta G_{\mathrm{EX}}$ of $-7.8 \mathrm{~kJ} / \mathrm{mol}$ that reflects the marked enhancement of the mixed-ligand sandwich complexes attributable to cooperative interactions between the quinoxaline group on $\mathbf{1}$ and one of the benzene groups on dibenzo-18-crown-6. For the solution containing 1 and dibenzo-18-crown- 6 with $\mathrm{RbCl}$ instead@fđKCl@Figure@c), (\$he@nixed-ligand@andwich complex, i.e., $(1+\text { dibenzo-18-crown- } 6+\mathrm{Rb})^{+}$, again dominated the spectrum, but the preference for formation of the mixed-ligand sandwiches was not as great as observed@nథrigure@2b,@nd@he@alculated $₫ \mathrm{G}_{\mathrm{Ex}}$ value

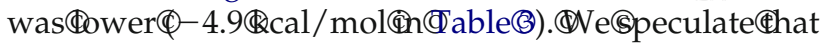
the $\Delta \mathrm{G}_{\mathrm{Ex}}$ value diminishes on going from $\mathrm{K}^{+}$to $\mathrm{Rb}^{+}$ because the greater size of $\mathrm{Rb}^{+}$reduces the overlap of the $\pi$-orbitals between 1 and dibenzo-18-crown-6.

The $\Delta G_{\mathrm{EX}}$ values obtained from this series of ESI-MS@xperiments@re@ummarized@n@Table@2.థror 15-crown-5, 18-crown-6, and aza-18-crown-6, the $\Delta \mathrm{G}_{\mathrm{EX}}$ values are positive, indicating that the formation of mixed-ligand sandwiches is disfavored relative to the formation of the homo-ligand complexes. With no additional functional groups on these three macrocycles, these were not expected to engage in
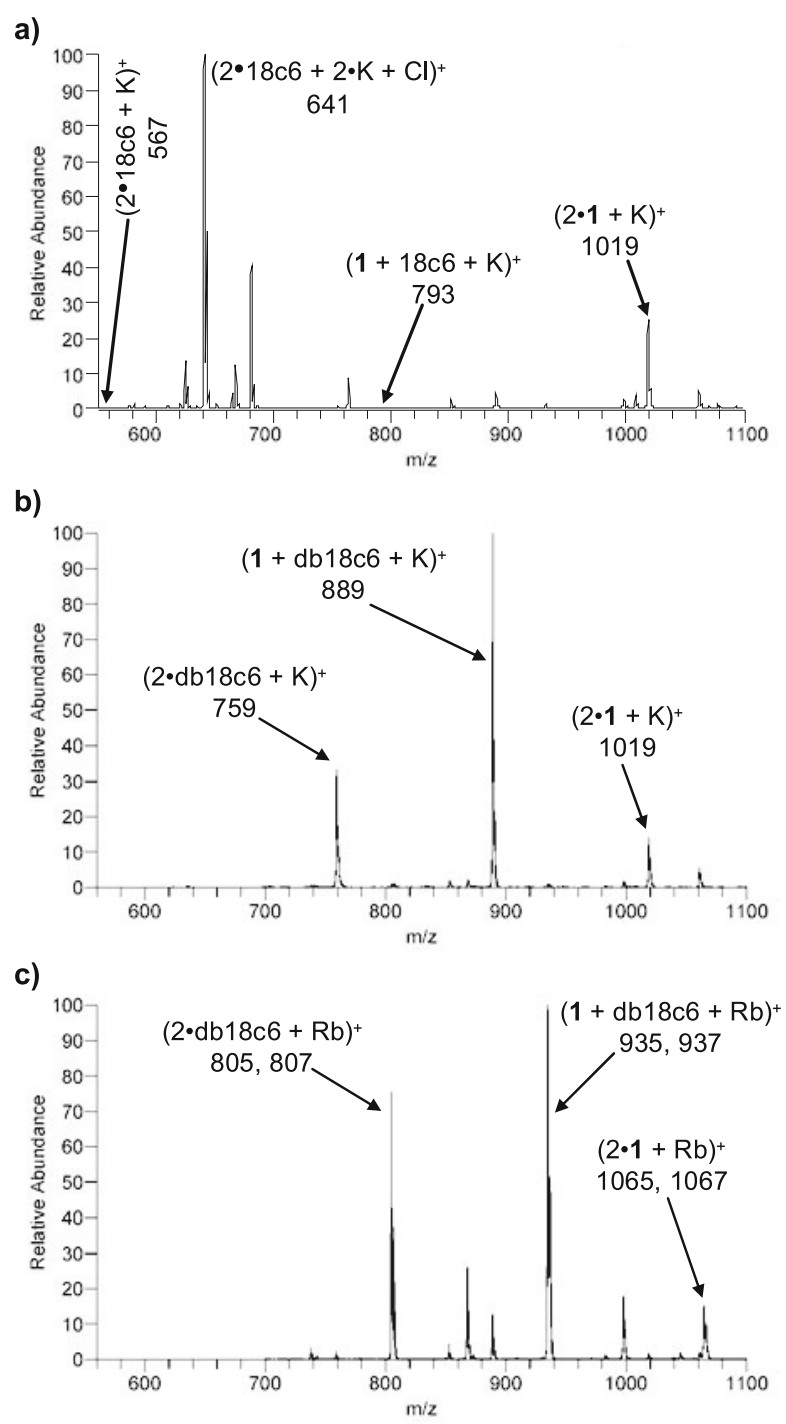

Figure 2. ESI-mass spectra of $\mathbf{1}$, a second macrocycle, and a metal ion in methanol. (a) 1, 18-crown-6 (18c6) and $\mathrm{K}^{+}$, (b) 1, dibenzo18-crown-6 (db18c6), and $\mathrm{K}^{+}$, and (c) 1, dibenzo-18-crown-6 and $\mathrm{Rb}^{+}$. No data was collected below $700 \mathrm{Th}$ in (c) to allow the sandwich complexes to be analyzed without peak broadening due to space-charge effects.

any special interactions with $\mathbf{1}$, other than the typical electrostatic interactions between the positive metal ion and the heteroatom donor groups that would specifically strengthen the mixed-ligand sandwich complexes. Dicyclohexano-18-crown-6, of similar size as dibenzo-18-crown-6, was evaluated to ensure that a particularly favorable steric situation was not responsible for any observed enhancement. The $\Delta \mathrm{G}_{\mathrm{EX}}$ with dicyclohexano-18-crown-6 was $+3.74 \mathrm{~kJ} / \mathrm{mol}$, again indicating that the formation of the mixedligand sandwich complex is disfavored.

The complexation of $\mathbf{1}$ and $\mathrm{K}^{+}$with two macrocycles possessing aromatic functional groups was also examined: benzo-18-crown-6 and dibenzo-18-crown-6. These two macrocycles have benzene groups capable of donating electron density to the quinoxaline moiety on $\mathbf{1}$. 
Table 3. Effect on $\Delta \mathrm{G}_{\mathrm{EX}}$ values for mixed-ligand sandwich complexes of 1 and either dibenzo-18-crown-6 or 18-crown-6 with various cations in methanol. Concentrations were $50 \mu \mathrm{M}$ in all cases. Errors reflect statistical deviation over three replicate measurements

\begin{tabular}{lccr}
\hline & \multicolumn{2}{c}{$\Delta \mathrm{G}_{\mathrm{EX}}(\mathrm{kJ} / \mathrm{mol})$} \\
\cline { 3 - 4 } & $\begin{array}{c}\text { lonic Radii } \\
\text { [50] }(\mathrm{pm})\end{array}$ & $\begin{array}{c}\text { dibenzo-18- } \\
\text { crown-6 }\end{array}$ & 18-crown-6 \\
\hline \hline $\mathrm{Na}^{+}$ & 116 & $-2.6 \pm 0.5$ & $7.9 \pm 0.8$ \\
$\mathrm{~K}^{+}$ & 152 & $-7.8 \pm 0.1$ & $7.2 \pm 0.8$ \\
$\mathrm{Rb}^{+}$ & 166 & $-4.9 \pm 0.3$ & $3.6 \pm 0.4$ \\
$\mathrm{Cs}^{+}$ & 181 & $-0.6 \pm 0.8$ & $5.7 \pm 0.3$ \\
$\mathrm{Sr}^{2+}$ & 127 & $0.5 \pm 0.7$ & $-10.9 \pm 0.7$ \\
$\mathrm{Ba}^{2+}$ & 143 & $-3.0 \pm 0.3$ & $-5.2 \pm 0.9$ \\
$\mathrm{Ag}^{+}$ & 129 & $2.4 \pm 0.5$ & $4 \pm 2$ \\
$\mathrm{NH}_{4}{ }^{+}$ & 161 & $-5.4 \pm 0.5$ & $3.6 \pm 0.9$ \\
\hline
\end{tabular}

With benzo-18-crown-6, a $\Delta \mathrm{G}_{\mathrm{EX}}$ of $-8.57 \mathrm{~kJ} / \mathrm{mol}$ was

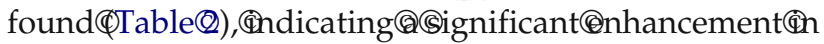
the formation of mixed-ligand sandwiches over that observed for the previous macrocycles. For dibenzo-18crown- 6 with 1 and $\mathrm{K}^{+}$, a $\Delta \mathrm{G}_{\mathrm{Ex}}$ of $-7.8 \mathrm{~kJ} / \mathrm{mol}$ was measured. These values indicate that with either benzo18-crown-6 or dibenzo-18-crown-6 the mixed-ligand sandwich complexes with $\mathbf{1}$ are very strongly favored. We speculate that the small increase in $\Delta \mathrm{G}_{\mathrm{EX}}$ for the sandwich formation involving 1 and benzo-18-crown- 6 versus 1 and dibenzo- 18 -crown- 6 is due to steric hindrance between the bulky cage group on 1 and the second benzo-group on dibenzo-18-crown-6-a hindrance not present with benzo-18-crown-6. The reactions of $\mathbf{1}$ with benzo-18-crown- 6 and dibenzo-18crown-6 also suggest that the cage group on 1 , included as an anchor point to allow attachment of the macrocycle to a polymer or surface, does not interfere with the $\pi$-stacking interactions.

In addition to the positive $\Delta \mathrm{G}_{\mathrm{Ex}}$ values obtained upon reaction of $\mathbf{1}$ and $\mathrm{K}^{+}$with the three reference macrocycles that did not possess aromatic groups, all of the observed sandwich complexes with the reference macrocycles had very low abundances in the mass spectra. These abundances were typically one to two orders of magnitude less than that of sandwich complexes formed with macrocycles containing aromatic functional groups, leading to the conclusion that even without any enhancement due to donor-acceptor interactions, $\pi$-stacking interactions significantly stabilize the formation of crown ether-metal sandwich complexes.

\section{Sandwich Complexes Involving 1 with Different Cations}

The formation of sandwich complexes containing different cations was examined in order to investigate the influence of the size and charge density of the cation on the self-assembly process. The Pauling ionic radii of the cations@ređisted@inable@.@hen@olutions@ontaining
1, dibenzo-18-crown-6, and each of the alkali metal chlorides were analyzed, a clear periodic trend emerged in the distribution of mixed-ligand sandwiches relative to the homo-ligand complexes as shown by the data in

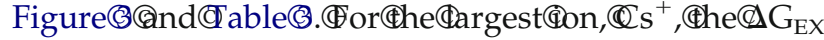
value was near zero, indicating that there was no significant preference for the formation of mixed-ligand sandwiches. The smallest ion, $\mathrm{Li}^{+}$, resulted in complexes that had very low abundances in the mass spectra, likely attributable to the poor ability of large crown ethers to form sandwich complexes with $\mathrm{Li}^{+}$ [27],@resumably@because@f@@mismatch@etween@he ion and cavity sizes. Because of the low abundances of complexes, $\Delta \mathrm{G}_{\mathrm{EX}}$ values could not be calculated in most cases@and@were@therefore@mitted@rom@Table@B.CThe largest enhancement was seen with $\mathrm{K}^{+}$, reaching a $\Delta \mathrm{G}_{\mathrm{EX}}$ value of $-7.8 \mathrm{~kJ} / \mathrm{mol}$, while $\mathrm{Na}^{+}$and $\mathrm{Rb}^{+}$ showed more modest enhancements in the formation of the mixed-ligand sandwich complexes. These results contrast starkly with solutions containing 1 and 18-

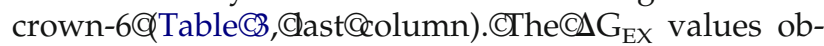
tained upon analysis of solutions containing 1, 18crown-6, and an alkali metal ion summarized

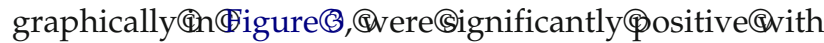
all the alkali metals, indicating a consistent preference against formation of the mixed-ligand complexes regardless of the size of the metal ion.

The large enhancement of mixed-ligand sandwich complexes between 1 and dibenzo-18-crown- 6 when $\mathrm{K}^{+}$ in the cation is likely the result of several size-related effects. Periodic trends are well known for 1:1 crown

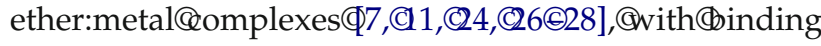
affinities in solution typically increasing as ions become large enough to interact optimally with more of the potential coordinating sites (oxygen heteroatoms). This size-selective effect is even more pronounced for sandwich complexes because larger ions are not encapsulated by a single macrocycle, thus facilitating coordination by two ligands. As a countering effect seen in the

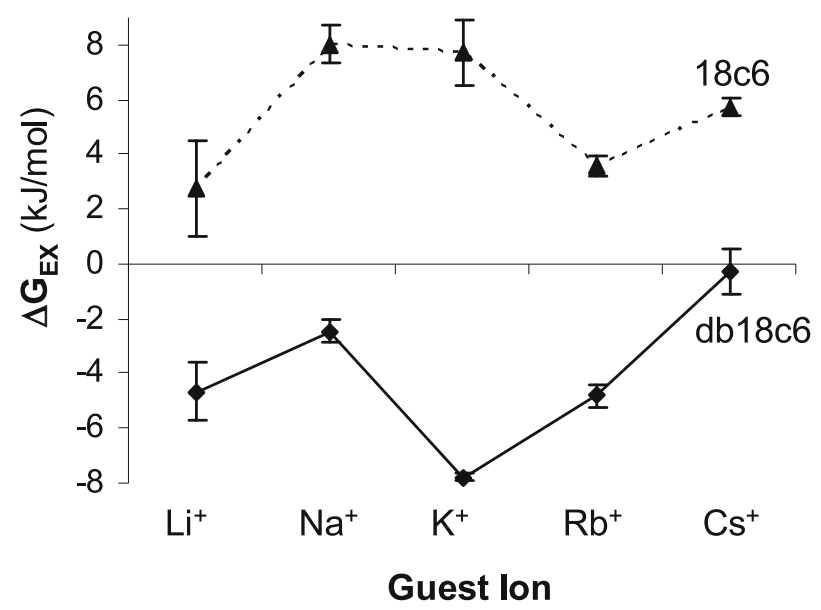

Figure 3. $\Delta \mathrm{G}_{\mathrm{EX}}$ for mixed-ligand sandwich complexes of $\mathbf{1}$ and either dibenzo-18-crown-6 (solid line) or 18-crown-6 (dotted line) with different alkali metal cations in methanol. 
present work, with very large ions such as $\mathrm{Cs}^{+}$, the spacing between the macrocyclic rings increases, reducing the overlap between the $\pi$-orbitals on the aromatic substituents of the benzo-crown ethers and $\mathbf{1}$ and decreasing the strength of their interactions.

In addition to the alkali metals, sandwich formation involving several other cations was evaluated as well. The alkaline earth cation $\mathrm{Sr}^{2+}$, with an ionic radius comparable to $\mathrm{Na}^{+}$, demonstrated no significant preference for the formation of mixed-ligand sandwiches involving 1 and dibenzo-18-crown-6, while with $\mathrm{Ba}^{2+}$, similar in size to $\mathrm{K}^{+}$, only a modestly negative $\Delta \mathrm{G}_{\mathrm{EX}}$ was observed. Both metals, however, resulted in lower $\Delta G_{E X}$ values for sandwich complexes incorporating $\mathbf{1}$ and@8-crown-6@Table(B).đThe@reater@harge@f@hese cations likely results in a shift in the relative contributions of the binding modes. Because of stronger electrostatic attractions between the doubly charged metal ions and the coordinating oxygen atoms, each macrocycle in a sandwich complex would be drawn closer to the metal ion and closer to the second coordinating ligand. The expected steric hindrance between the quinoxaline and cage groups on $\mathbf{1}$ and the benzene groups of dibenzo-18-crown-6 likely becomes a punitive factor, causing a decrease in the formation of mixed-ligand sandwiches. 18-Crown-6 lacks any bulky substituent, and thus the enhancement in sandwich formation due to the higher charge density of the alkaline earth metal ion is not mitigated by counterproductive steric effects.

To evaluate whether the complexation of $\mathbf{1}$ was influenced directly by the quinoxaline moiety on $\mathbf{1}$, sandwich complex formation with $\mathrm{Ag}^{+}$was examined (Table@B).CWith@silver's@known@affinity@for@nitrogen

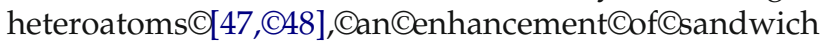
formation might be expected relative to that observed for complexation of $\mathrm{K}^{+}$, which has a similar ionic radius and no special affinity for nitrogen. No such enhancement is observed, however, and the positive $\Delta G_{\mathrm{EX}}$ values observed for $\mathrm{Ag}^{+}$with 1 and either dibenzo-18crown-6 $(2.4 \mathrm{~kJ} / \mathrm{mol})$ or 18-crown-6 $(4 \mathrm{~kJ} / \mathrm{mol})$ indicate that silver is a poor choice overall for mixed-ligand sandwich complex formation. This result may be related to the general preference of $\mathrm{Ag}^{+}$to adopt a linear coordination geometry which creates an orbital alignmentథroblem@hen@orming@andwich@omplexes\$50].

Finally, to determine whether cations other than metals could result in enhancement in mixed-ligand sandwich formation, solutions containing $\mathbf{1}$, a second macrocycle, and the ammonium ion were analyzed. With an ionic radius similar to $\mathrm{Rb}^{+}$, a roughly spherical shape, and a closed valence, $\mathrm{NH}_{4}{ }^{+}$led to a significantly negative $\Delta \mathrm{G}_{\mathrm{EX}}$ value $(-5.4 \mathrm{~kJ} / \mathrm{mol})$ for the mixedligand sandwich complexes containing 1 and dibenzo18-crown-6, its enhancement second only to $\mathrm{K}^{+}$in this study@(Table@B). $\mathbb{C S}$ Since $\mathrm{CNH}_{4}{ }^{+}$binds to crown ethers though hydrogen bonding interactions rather than metal-ligand coordination, this result suggests that the use of donor-acceptor $\pi$-stacking to direct self-assembly

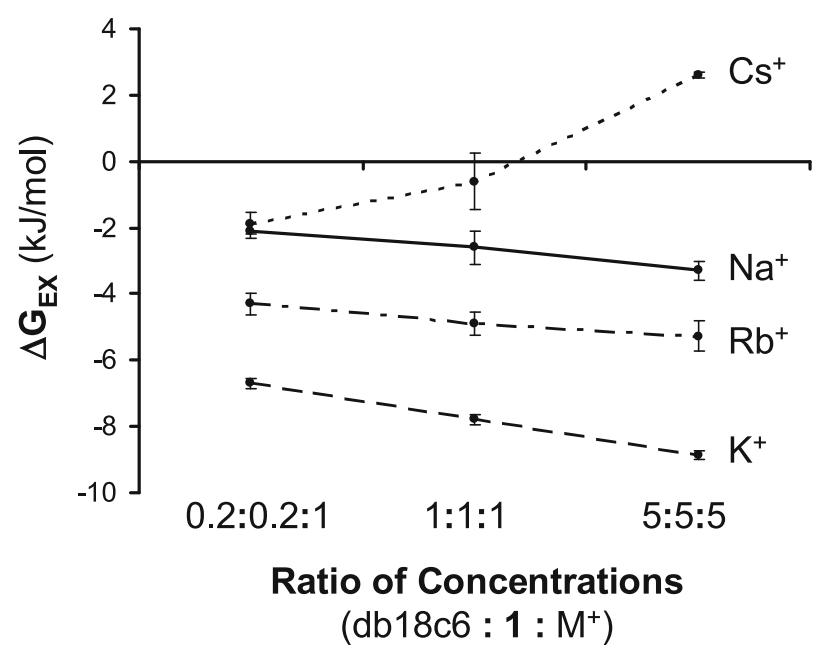

Figure 4. Result of measuring $\Delta \mathrm{G}_{\mathrm{EX}}$ at different relative concentrations of the ligands (dibenzo-18-crown-6 and 1) and alkali metal cations. Errors reflect statistical deviation over three replicate measurements.

of sandwich complexes might be possible with a wide range of cations.

\section{Concentration Dependence of $\Delta G_{E X}$ Measurements}

A common endeavor when evaluating the binding of novel ligands is to examine how the binding behavior changes with different relative concentrations of the

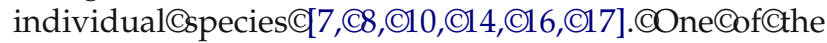
advantages of evaluating the binding information thermochemically, however, is that the results should display no dependence on solution concentrations. Accordingly, as a final test of the experimental method, 1 and dibenzo-18-crown- 6 were again analyzed with the alkali metals as described above. This time, however, while the metal concentrations remained unchanged, solutions were analyzed in which the ligand concentrations were both increased and decreased fivefold. With $\mathrm{Na}^{+}, \mathrm{K}^{+}$, and $\mathrm{Cs}^{+}$, the three metal cations that most readily formed mixed-ligand complexes, increasing ligand concentrations caused very small decreases in the calculated $\Delta \mathrm{G}_{\mathrm{EX}}$ values that were barely significant with respect to variations among the replicate measurements (Figure@).@ith@s ${ }^{+}$, $₫$ owever, @n@increase $₫\left(₫ \mathrm{G}_{\mathrm{EX}}\right.$ was observed with increasing ligand concentrations, possibly the result of in-source fragmentation of the fairly weak $\mathrm{Cs}^{+}$sandwich complexes. Changing the relative concentration had virtually no effect on the measured values of $\Delta \mathrm{G}_{\mathrm{EX}}$ in most cases, illustrating the validity of these thermochemical measurements, particularly for the mixed-ligand complexes displaying the greatest enhancement in stability.

\section{Conclusions}

Through ESI-MS experiments, the novel crown ether 1 containing an electron-poor quinoxaline moiety was 
demonstrated to form 2:1 macrocycle:cation sandwich complexes preferentially with secondary macrocycles containing electron-rich benzene substituents through donor-acceptor $\pi$-stacking interactions between the aromatic side groups. The magnitude of the enhancement of these mixed-ligand sandwich complexes was found to be highly dependent on the size of the encapsulated cation, with a preference for cations that maximize the effective interactions of each macrocycle with the cation yet minimize steric effects between the macrocycles. Similar experiments with dibenzo-18-crown- 6 and $\mathrm{K}^{+}$ yielded no additional stabilization of the mixed ligand complexes with any of the other crown ethers examined. That such donor-acceptor $\pi$-stacking interactions so readily enhance the formation of crown ether sandwich complexes confirms their utility as building blocks in self-assembled molecular structures. The ESI-MS strategy presented in this work should be applicable to those biological systems in which $\pi$-stacking interactions play a role.

\section{Acknowledgments}

The authors thank the Robert A. Welch Foundation [grants F-1155 (JSB) and B-0963 (APM)], the National Science Foundation [CHE0315337], and the U. S. Department of Energy [grant DE-FG0798ER14936 (APM)] for financial support of this study. In addition, they thank Dr. Rasapalli Sivappa, Department of Chemistry, University of North Texas, for assistance with the synthesis and characterization of $\mathbf{1}$.

\section{References}

1. Ho, P. K.-H.; Filas, R. W.; Abusch-Magder, D.; Bao, Z. Orthogonal Self-Aligned Electroless Metallization by Molecular SelfAssembly. Langmuir 2002, 18, 9625-9628.

2. Ahrens, M. J.; Sinks, L. E.; Rybtchinski, B.; Liu, W.; Jones, B. A.; Giaimo, J. M.; Gusev, A. V.; Goshe, A. J.; Tiede, D. M.; Wasielewski, M. R. Self-Assembly of Supramolecular LightHarvesting Arrays from Covalent Multi-Chromophore Perylene-3,4:9,10-Bis(dicarboximide) Building Blocks. J. Am. Chem. Soc. 2004, 126, 8284-8294.

3. Zhang, S. Emerging Biological Materials Through Molecular Self-Assembly. Biotech. Adv. 2002, 20, 321-339.

4. Schalley, C. A. Supramolecular Chemistry Goes Gas Phase: The Mass Spectroscopic Examination of Noncovalent Interactions in Host-Guest Chemistry and Molecular Recognition. Int. J. Mass Spectrom. 2000, 194, 11-39.

5. Dearden, D. V.; Liang, Y.; Nicoll, J. B.; Kellersberger, K. A. Study of Gas-Phase Molecular Recognition Using Fourier Transform Ion Cyclotron Resonance Mass Spectrometry (FTICR/MS). J. Mass Spectrom. 2001, 36, 989-997.

6. Przybylski, M.; Glocker, M. O. Electrospray Mass Spectrometry of Biomacromolecular Complexes with Noncovalent Interactions-New Analytical Perspectives for Supramolecular Chemistry and Molecular Recognition Processes. Angew. Chem. Int. Ed. Engl. 1996, 35, 807-826.

7. Williams, S.; Blair, S. M.; Brodbelt, J. S.; Huang, X.; Bartsch, R. A. Determination of Alkali Metal Cation Selectivities of Dibenzo-16-Crown-5 Lariat Ethers with Ether Pendant Groups by Using Electrospray Ionization Quadrupole Ion Trap Mass Spectrometry. Int. J. Mass Spectrom. 2001, 212, 389-401.

8. Blair, S. M.; Brodbelt, J. S.; Marchand, A. P.; Kumar, K. A.; Chong, H. S. Evaluation of Binding Selectivities of Caged
Crown Ligands Toward Heavy Metals by Electrospray Ionization/Quadrupole Ion Trap Mass Spectrometry. Anal. Chem. 2000, 72, 2433-2445.

9. Kempen, E. C.; Brodbelt, J. S. A Method for the Determination of Binding Constants by Electrospray Ionization Mass Spectrometry. Anal. Chem. 2000, 72, 5411-5416.

10. Williams, S. M.; Brodbelt, J. S.; Marchand, A. P.; Cal, D.; Mlinaric-Majerski, K. Metal Complexation of Thiacrown Ether Macrocycles by Electrospray Ionization Mass Spectrometry. Anal. Chem. 2002, 74, 4423-4433.

11. Sherman, C. L.; Brodbelt, J. S. An Equilibrium Partitioning Model for Predicting Response to Host-Guest Complexation in Electrospray Ionization Mass Spectrometry. Anal. Chem. 2003, 75, 1828-1836

12. Kempen, E. C.; Brodbelt, J. S.; Bartsch, R. A.; Jang, Y.; Kim, J. S. Investigation of Alkali Metal Cation Selectivities of Lariat Ethers by Electrospray Ionization Mass Spectrometry. Anal. Chem. 1999, 71, 5493-5500.

13. Blair, S. M.; Brodbelt, J. S.; Reddy, G. M.; Marchand, A. P. Evaluation of Binding Selectivities of Bis-Crowned Clefts by Electrospray Ionization/Quadrupole Ion Trap Mass Spectrometry. J. Mass Spectrom. 1998, 33, 721-728.

14. Blair, S. M.; Kempen, E. C.; Brodbelt, J. S. Determination of Binding Selectivities in Host-Guest Complexation by Electrospray/Quadrupole Ion Trap Mass Spectrometry. J. Am. Soc. Mass Spectrom. 1998, 9, 1049-1059.

15. Jorgensen, T. J. D.; Roepstorff, P.; Heck, A. J. R. Direct Determination of Solution Binding Constants for Noncovalent Complexes between Bacterial Cell Wall Peptide Analogues and Vancomycin Group Antibiotics by Electrospray Ionization Mass Spectrometry. Anal. Chem. 1998, 70, 4427-4432.

16. Young, D.-S.; Hung, H.-Y.; Liu, L. K. An Easy and Rapid Method for Determination of Stability Constants by Electrospray Ionization Mass Spectrometry. Rapid Commun. Mass Spectrom. 1997, 11, 769-773.

17. Young, D.-S.; Hung, H.-Y.; Liu, L. K. Estimation of Selectivities and Relative Cationization Efficiencies of Different [Crown + $\mathrm{M}]^{+}$by Electrospray Mass Spectrometry. J. Mass Spectrom. 1997, 32, 432-437.

18. Schalley, C. A.; Catellano, R. K.; Brody, M. S.; Rudkevich, D. M.; Siuzdak, G.; Rebek, J., Jr. Investigating Molecular Recognition by Mass Spectrometry: Characterization of Calixarene-Based Self-Assembling Capsule Hosts with Charged Guests. J. Am. Chem. Soc. 1999, 121, 4568-4579.

19. Mansikkamaki, H.; Nissinen, M.; Schalley, C. A.; Rissanen, K. Self-Assembling of Resorcinarene Capsules: Solid and Gas Phase Studies on Encapsulation of Small Alkyl Ammonium Cations. New J. Chem. 2003, 27, 88-97.

20. Nuutinen, J. M. J.; Irico, A.; Vincenti, M.; Dalcanale, E.; Pakarinen, J. M. H.; Vainiotalo, P. Gas-Phase Ion-Molecule Reactions between a Series of Protonated Diasteriomeric Cavitands and Neutral Amines Studied by ESI-FTICRMS: GasPhase Inclusion Complex Formation. J. Am. Chem. Soc. 2000, 122, 10090-10100.

21. Zhang, H.; Paulsen, E.; Walker, K. A.; Krzysztof, E.; Dearden, D. V. Cucurbit[6]Uril Pseudorotaxanes: Distinctive Gas-Phase Dissociation and Reactivity. J. Am. Chem. Soc. 2003, 125, 9284-9285.

22. Nicoll, J. B.; Dearden, D. V. Reactions of Multidentate Ligands with Ligated Alkali Cation Complexes: Self-Exchange and "Sandwich" Complex Formation Kinetics of Gas Phase Crown Ether-Alkali Cation Complexes. Int. J. Mass Spectrom. 2001, 204, 171-183.

23. Wu, H.-F.; Huan, S.-M.; Wu, C.-F. Conformational Analysis and Binding Affinity Determination for Host-Guest Complexation of Alkali Metal Ions with Bis-Crown Ethers by Electro- 
spray Mass Spectrometry and Molecular Modeling. Eur. J. Mass Spectrom. 2002, 8, 375-380.

24. Shen, N.; Pope, R. M.; Dearden, D. V. Fundamental Factors Controlling the Exchange of Multidentate Ligands: Displacement of 12-Crown-4 and Triglyme from Complexes with Divalent Alkaline Earth Cations. Int. J. Mass Spectrom. 2000, 195/196, 639-652.

25. Oshima, T.; Matsuda, F.; Fukushima, K.; Tamura, H.; Matsubayashi, G.; Arakawa, R. Selective Cation Binding of Crown Ether Acetals in Electrospray Ionization Mass Spectrometry. J. Chem. Soc. Perkin Trans. 2 1998, 145-148.

26. Marchand, A. P.; Kumar, K. A.; McKim, A. S.; Alihodzic, S.; Chong, H.-S.; Krishnudu, K.; Takhi, M.; Mlinaric-Majerski, K.; Kragol, G.; Sumanovac, T. Novel Cage-Annulated Crown Ethers, Cryptands, and Molecular Boxes: A New Class of Ionophores for Selective Ion Complexation. Kem. Ind. 2001, 50,129-138

27. Arnaud-Neu, F.; Delgadoand, R.; Chaves, S. Critical Evaluation of Stability Constants and Thermodynamic Functions of Metal Complexes of Crown Ethers. Pure Appl. Chem. 2003, 75, 71-102.

28. Seyedi, S. M.; Gouran, A.; Malekshah, T. Synthesis and Extraction Properties of New Bis-Crown Ethers Derived from Stereoisomer of 1,2-Cyclohexanediols for Alkali and Alkaline Earth Metal Cations. Heterocycles 2003, 60, 113-119.

29. Izatt, R. M.; Bradshaw, J. S.; Nielsen, S. A.; Lamb, J. D.; Christensen, J. J.; Sen, D. Thermodynamic and Kinetic Data for Cation-Macrocycle Interaction. Chem. Rev. 1985, 85, 271-339.

30. Marchand, A. P.; Reddy, G. M.; Zaragoza, F.; Bartsch, R. A.; Eley, M. D. Synthesis of a Novel, Tetra-Crowned Molecular Cleft and Studies of its Selectivity in Alkali Metal Ion Complexation. Tetrahedron Lett. 1993, 34, 5377-5380.

31. Bartsch, R. A.; Eley, M.; Marchand, A. P.; Shukla, R.; Kumar, K. A. Synthesis of Bis- and Tetra-Crowned Clefts and Studies of Their Selectivities in Metal Ion Complexation. Tetrahedron 1996, 52, 8979-8988.

32. Hunter, C. A.; Lawson, K. R.; Perkins, J.; Urch, C. J. Aromatic Interactions. J. Chem. Soc. Perkin Trans. 2 2001, 5, 651-669.

33. Kamieth, M.; Burkert, U.; Corbin, P. S.; Dell, S. J.; Zimmerman, S. C.; Klärner, F.-G. Molecular Tweezers as Synthetic Receptors: Molecular Recognition of Electron-Deficient Aromatic Substrates by Chemically Bonded Stationary Phases. Eur. J. Org. Chem. 1999, 11, 2741-2749

34. Cloninger, M. J.; Whitlock, H. W. A Synthetic Receptor Which Uses Multiple Edge-Face Interactions to Bind Aromatic Guests. J. Org. Chem. 1998, 63, 6153-6159.

35. Reek, J. N. H.; Priem, A. H.; Engelkamp, H.; Rowan, A. E.; Elemans, J. A. A. W.; Nolte, R. J. M. Binding Features of Molecular Clips. Separation of the Effects of Hydrogen Bonding and $\pi-\pi$ Interactions. J. Am. Chem. Soc. 1997, 119, 99569964.

36. Gokel, G. W.; De Wall, S. L.; Meadows, E. S. Experimental Evidence for Alkali Metal Cation- $\pi$ Interactions. Eur. J. Org. Chem. 2000, 2967-2978.

37. Zacharias, N.; Dougherty, D. A. Cation $-\pi$ Interactions in Ligand Recognition and Catalysis. Trends Pharmacol. Sci. 2002, $23,281-287$.
38. Meyer, E. A.; Castellano, R. K.; Diederich, F. Interactions with Aromatic Rings in Chemical and Biological Recognition. Angew. Chem. Int. Ed. 2003, 42, 1210-1250.

39. Ferguson, S. B.; Sanford, E. M.; Seward, E. M.; Diederich, F. Cyclophane-Arene Inclusion Complexation in Protic Solvents: Solvent Effects Versus Electron Donor-Acceptor Interactions. J. Am. Chem. Soc. 1991, 113, 5410-5419.

40. Marchand, A. P.; Chong, H.-S.; Alihodzic, S.; Watson, W. H.; Bodige, S. G. Synthesis and Alkali Metal Picrate Extraction Capabilities of Novel, Cage-Functionalized, Pyridine Containing Crown Ethers and Cryptands. Tetrahedron 1999, 55, 96879696.

41. Wang, W.; Kitova, E. N.; Klassen, J. S. Influence of Solution and Gas Phase Processes on Protein-Carbohydrate Binding Affinities Determined by Nanoelectrospray Fourier Transform Ion Cyclotron Resonance Mass Spectrometry. Anal. Chem. 2003, 75, 4945-4955.

42. Zampronio, C. G.; Giannakaopulous, A. E.; Zeller, M.; Bitziou, E.; Macpherson, J. V.; Derrick, P. J. Production and Properties of Nanoelectrospray Emitters Used in Fourier Transform Ion Cyclotron Resonance Mass Spectrometry: Implications for Determination of Association Constants for Noncovalent Complexes. Anal. Chem. 2004, 76, 5172-5179.

43. Sannes-Lowery, K. A.; Griffey, R. H.; Hofstadler, S. A. Measuring Dissociation Constants of RNA and Aminoglycoside Antibiotics by Electrospray Ionization Mass Spectrometry. Anal. Biochem. 2000, 280, 264-271.

44. Greig, M. J.; Gaus, H.; Cummins, L. L.; Sasmor, H.; Griffey, R. H. Measurement of Macromolecular Binding Using Electrospray Mass Spectrometry. Determination of Dissociation Constants for Oligonucleotide-Serum Albumin Complexes. J. Am. Chem. Soc. 1995, 117, 10765-10766.

45. Loo, J. A.; Hu, P.; McConnell, P.; Mueller, W. T.; Sawyer, T. K.; Thanabal., V. A Study of Src SH2 Domain ProteinPhosphopeptide Binding Interactions by Electrospray Ionization Mass Spectrometry. J. Am. Soc. Mass Spectrom. 1997, 8, 234-243.

46. Lim, H. K.; Hsieh, F. Y. L.; Ganem, B.; Henion, J. Recognition of Cell-Wall Peptide Ligands by Vancomycin Group Antibiotics: Studies Using Ion Spray Mass Spectrometry. J. Mass Spectrom. 1995, 30, 708-714.

47. El Aribi, H.; Rodriquez, C. F.; Shoeib, T.; Ling, Y.; Hopkinson, A. C.; Siu, K. W. M. Threshold Collision-Induced Dissociation Determination and Molecular Orbital Calculations of the Binding Energies of Sodium and Silver Ions to Small NitrogenContaining Ligands. J. Phys. Chem. A 2002, 106, 8798-8805.

48. Ma, N. L. How Strong is the $\mathrm{Ag}^{+}$-Ligand Bond? Chem. Phys. Lett. 1998, 297, 230-238.

49. Buschmann, H.-J. Stability Constants and Thermodynamic Data for Complexes of 12-Crown-4 with Alkali Metal and Alkaline-Earth Cations in Methanol Solutions. J. Sol. Chem. 1987, 16, 181-190.

50. Cotton, F. A.; Wilkinson, G.; Murillo, C. A.; Bochmann, M. Advanced Inorganic Chemistry, 6th ed. John Wiley and Sons, New York, 1999, pp. 1085, 1302-1303. 